\title{
Differentiation of Crystal Cells, Gravity-Sensing Cells in the Placozoan Trichoplax adhaerens
}

Tatiana D. Mayorova

Citation: Mayorova, T.D.

Differentiation of Crystal Cells, Gravity-Sensing Cells in the Placozoan Trichoplax adhaerens. J. Mar Sci. Eng. 2021, 9, 1229. https:// doi.org/10.3390/jmse9111229

Academic Editor: Alexandre Lobo-da-Cunha

Received: 9 October 2021

Accepted: 4 November 2021

Published: 6 November 2021

Publisher's Note: MDPI stays neutral with regard to jurisdictional claims in published maps and institutional affiliations.

Copyright: (C) 2021 by the author. Licensee MDPI, Basel, Switzerland. This article is an open access article distributed under the terms and conditions of the Creative Commons Attribution (CC BY) license (https:/ / creativecommons.org/licenses/by/ $4.0 /)$.
Laboratory of Neurobiology, Structural Cell Biology Section, National Institute of Neurological Disorders and Stroke, National Institutes of Health, 49 Convent Drive, Bethesda, MD 20892, USA; tatiana.mayorova@nih.gov or mayorova@wsbs-msu.ru

\begin{abstract}
Trichoplax adhaerens are simple animals with no nervous system, muscles or body axis. Nevertheless, Trichoplax demonstrate complex behaviors, including responses to the direction of the gravity vector. They have only six somatic cell types, and one of them, crystal cells, has been implicated in gravity reception. Multiple crystal cells are scattered near the rim of the pancake-shaped animal; each contains a cup-shaped nucleus and an intracellular crystal, which aligns its position according to the gravity force. Little is known about the development of any cell type in Trichoplax, which, in the laboratory, propagate exclusively by binary fission. Electron and light microscopy were used to investigate the stages by which crystal cells develop their mature phenotypes and distributions. Nascent crystal cells, identified by their possession of a small crystal, were located farther from the rim than mature crystal cells, indicating that crystal cells undergo displacement during maturation. They were elongated in shape and their nucleus was rounded. The crystal develops inside a vacuole flanked by multiple mitochondria, which, perhaps, supply molecules needed for the biomineralization process underlying crystal formation. This research sheds light on the development of unique cells with internal biomineralization and poses questions for further research.
\end{abstract}

Keywords: Trichoplax; Placozoa; cell type evolution; gravireception; crystal cell; biomineralization; lithocyte

\section{Introduction}

Trichoplax adhaerens (Schulze, 1883) belongs to phylum Placozoa, a group of unique marine animals, the appearance of which is strikingly different from animals in other phyla. They have small (about $1 \mathrm{~mm}$ in diameter), flat, pancake-shaped bodies that undergo amoeboid-like changes in outline [1-3]. They adhere to and crawl on substrates, propelled by monociliated cells on the ventral side [4]. They lack a morphological anterior-posterior body axis and can crawl in any direction [5]. Using chemotaxis, Trichoplax find their food-cyanobacteria and microalgae [6]. Unlike most other metazoans, Trichoplax digest their food externally, secreting digestive enzymes into the cleft between their body and the substrate [4]. According to the majority of phylogenetic studies, Placozoa are sister to the clade that includes Cnidaria and Bilateria [7-10]. Their simple body plans and lifestyles make them a useful model for research aimed at understanding metazoan evolution.

Trichoplax has six broadly defined somatic cell types [3]. The main components of the dorsal and ventral epithelia are monociliary dorsal and ventral epithelial cells, respectively $[4,11,12]$. The ventral epithelium also includes mucocytes, several subtypes of peptidergic secretory cells, and lipophils, involved in secretion of digestive enzymes (reviewed by [13]). Each of these cell types is arranged in a distinctive radial pattern [14,15]. Fiber cells, implicated in innate immunity, are arrayed in a layer between the dorsal and ventral epithelia $[3,16,17]$. Crystal cells, each containing a birefringent crystal, are confined to a narrow zone near the rim where the dorsal and ventral epithelia meet $[3,18]$.

Although there is molecular evidence of sexual reproduction in a clade of placozoans collected from the Caribbean [19], placozoans maintained in culture propagate exclusively 
asexually. They divide frequently by binary fission or bud off spheric swarmers [5,20-23]. Analysis of cell proliferation shows large numbers of mitotic cells throughout the body $[17,24]$. However, no information is available about the generation and differentiation of any cell type. The goal of this research was to learn about the development of one of the somatic cell types, crystal cells.

Crystal cells have distinctive morphological characteristics, the most prominent of which is possession of an intracellular birefringent crystal composed of calcium carbonate in the form of aragonite $[3,18]$. Mitochondria are closely apposed to the crystal and the cytoplasm is clear and almost free of organelles. The nucleus is cup-shaped and aligned along the plasma membrane of one side of the cell, with the opening of the cup oriented toward the rim of the body. Crystal cells are thought to be gravity receptors because the crystal shifts in the direction of gravity [18]. Trichoplax typically have multiple $(\sim 75)$ crystal cells located around their circumference [3]. However, some individuals have few or no crystal cells. Animals with typical numbers of crystal cells were able to maintain normal moving behavior, a random walk, when on a vertical substrate, whereas animals with few or no crystal cells drifted downwards, suggesting that crystal cells are needed to receive and respond to information about body orientation [18]. Whether and how crystal cells communicate with the ciliated cells that mediate crawling is unknown. Crystal cells are reported to generate action potentials [25] but no synaptic connections between crystal cells and other cell types are apparent in ultrastructural studies. Better understanding of Trichoplax gravireception may come from promising new experimental setups testing behavior and gene expression in different gravity conditions [26].

Crystal cells resemble lithocytes, gravity detectors found in only a few other animal groups (i.e., Acoela, flatworms) $[27,28]$. Ultrastructural studies of lithocytes have shed light on the organization of statocysts and gravity reception in these groups. However, little information is available about the development of lithocytes or the chemical bases of biomineralization in these cells. The present work uses electron and light microscopy to reveal the stages by which crystal cells, lithocytes of Trichoplax, acquire their distinctive mature morphotype and distribution. Histochemical stains for molecules implicated in extracellular calcium carbonate biomineralization in other animals failed to stain crystal cells, suggesting that the formation of their aragonite crystals depends on different biochemical pathways.

\section{Materials and Methods}

Animal care. Trichoplax adhaerens culture of the Grell (1971) strain (a gift from Leo Buss, Yale University) was maintained in artificial seawater (ASW) (Instant Ocean, Blacksburg, VA, USA) at room temperature with 1\% Micro Algae Grow (Florida Aqua Farms, Dade City, FL, USA) as described earlier [29]. Trichoplax medium was partially refreshed once a week. Animals were fed red algae (Rhodamonas salina, Provasoli-Guillard National Center for Culture of Marine Plankton, East Boothbay, ME, USA).

Transmission electron microscopy. Trichoplax were frozen and freeze substituted as described elsewhere [3]. Samples were embedded in Epon resin and ultrathin sections were cut in series of 5-7 continuous sections in order to examine the one with the largest void from a crystal. After a short counterstaining with uranyl acetate and lead citrate, sections were examined at 80 or $120 \mathrm{KV}$ in a JEOL 200-CX electron microscope (JEOL, Tokyo, Japan) and were photographed with an AMT camera mounted below the column.

Light microscopy. Trichoplax were placed on salinized cover slips and fixed in a mixture of $4 \%$ paraformaldehyde (EMS, Hatfield, PA, USA) and $0.25 \%$ glutaraldehyde (EMS, USA) in buffered ASW ( $\mathrm{NaCl} 400 \mathrm{mM} ; \mathrm{MgCl}_{2} 5 \mathrm{mM} ; \mathrm{CaCl}_{2} 2 \mathrm{mM}$; sucrose $300 \mathrm{mM}$; HEPES $30 \mathrm{mM}$; pH 7.4) for two hours.

For crystal size evaluation, the samples were rinsed from fixative cocktail with PBS (pH 7.4), stained with Hoechst dye (1:2000; Life Technologies, Carlsbad, CA, USA), mounted in Vectashield (Vector Laboratories, Burlingame, CA, USA), and examined in a LSM 510 microscope (Carl Zeiss Microscopy, Thornwood, NY, USA). Images were cap- 
tured with DIC and fluorescence optics with $405 \mathrm{~nm}$ illumination using 40X NA 1.2 or 63X NA1.4 objectives.

For labeling with different dyes, samples were rinsed in PBS and decalcified in $10 \%$ EDTA overnight. The following combinations of dyes were applied after rinsing with PBS with $0.2 \%$ Tween (PBST):

1. Calcofluor White (Sigma-Aldrich; St. Louis, MO, USA) diluted 1:1000 in PBST was applied for two hours; after washing with PBS, propidium iodide was added for $20 \mathrm{~min}$.

2. Samples were incubated in blocking buffer ( $3 \%$ normal goat serum, $2 \%$ horse serum, $1 \%$ BSA in PBS) for one hour and then Col-F dye ( $20 \mu \mathrm{M}$ final concentration; ImmunoChemistry Technologies, Bloomington, MN, USA) was applied for 30 min at $37^{\circ} \mathrm{C}$. After washing with PBS, Hoechst was added for $20 \mathrm{~min}$.

3. A cocktail of seven fluorescein conjugated lectins (Concanavalin A, Dolichos biflorus agglutinin, peanut agglutinin, Ricinus communis agglutinin, soybean agglutinin, Ulex europaeus agglutinin, and wheat germ agglutinin, all from Vector Laboratories, USA) each diluted 1:200 in PBST and Hoechst was applied for two hours.

The samples were rinsed from dyes with PBS, mounted in Vectashield, and examined in a LSM 510 microscope. Crystal cells were identified by a cup-shaped nucleus. Stacks of images were obtained with 63X NA 1.4 objective and were then processed with Fiji software.

Crystal measurement and statistics. A series of optical sections through crystal cells were captured with DIC optics. For each cell, the optical section capturing the crystal in focus was selected for measurement. The longest diagonal of the bright, rectangular crystal and the distance between the crystal and the rim of the animal were measured with the straight-line tool of Fiji 2.0.0-rc-49/1.51d software (NIH, Bethesda, MD, USA).

To analyze correlation between crystal size and its position, statistics treatment was performed with Past 3.14 software (Natural History Museum, Oslo, Norway). Since the normality tests were not passed, Spearman's rank correlation coefficient was calculated. To exclude heteroscedasticity, a Breusch Pagan test was applied.

\section{Results}

The developmental sequence by which crystal cells acquire their mature phenotype and distribution was investigated by transmission electron microscopy of thin sections and light microscopy in wholemounts.

Morphology of differentiating crystal cells. Morphologically, commitment of a cell to differentiation into crystal cell can be detected when a small crystal begins to grow in a vacuole surrounded by mitochondria (Figure $1 \mathrm{~A}$ ). The crystal in a differentiating crystal cell is several times smaller than crystals typically observed in mature crystal cells (compare Figure $1 \mathrm{~A}, \mathrm{C}$ ). The content of the vacuole bathing the growing crystal is homogeneous and electron lucent (Figure 1A, inset). The differentiating crystal cell is elongated and irregular in outline (Figure 1A). The nucleus is round, oval or bean-shaped (Figure $1 \mathrm{~A}, \mathrm{~A}^{\prime}$ ) and may not be flattened to the plasma membrane (Figure 1A). The cytoplasm contains ribosomes and organelles.

As differentiation progresses, the crystal becomes bigger and occupies more of the vacuole internal space (Figure 1B). The nucleus adheres to one side of the cell (Figure 1B, $\mathrm{B}^{\prime}$ ) and gradually assumes the shape of a cup with thick walls (Figure $\left.1 B, B^{\prime}\right)$. The shape of the cell becomes oval and its outline is mostly smooth but bears small protrusions (Figure 1B).

In mature crystal cells, the crystal is tightly enclosed within the vacuole membrane (Figure 1C). The nucleus is flattened in cross section (Figure 1C, $\mathrm{C}^{\prime}$ ) and closely aligned along the plasma membrane on one side of the cell (Figure 1C). The cytoplasm contains few ribosomes and organelles. The cell is round, and its surface is mainly smooth but has small, thin protrusions (Figure 1C). The cells have extensive areas of close apposition to one or more ciliated epithelial cells and also interact with fiber cell bodies and processes [18]. 


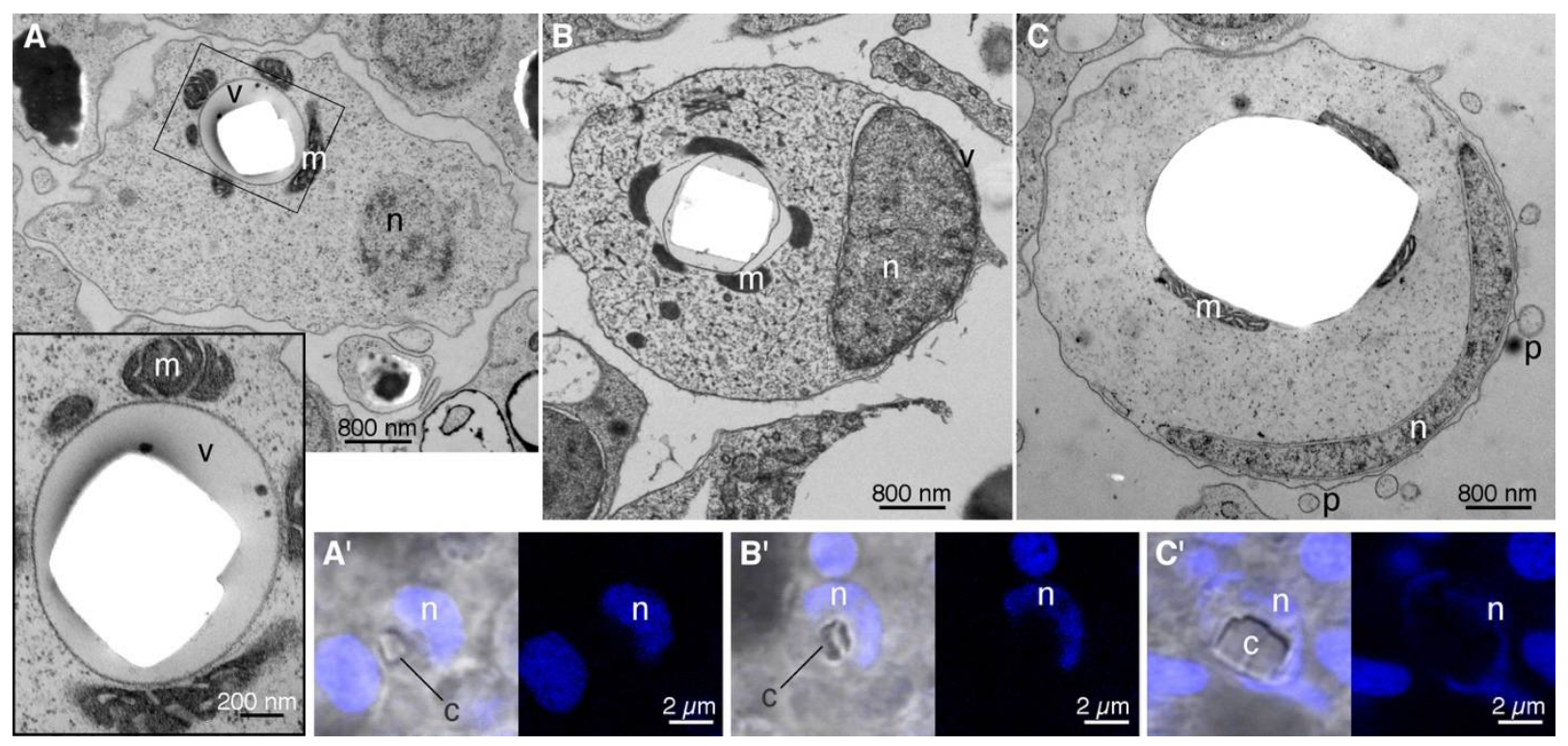

Figure 1. Transmission electron and light microscopy of developing and mature crystal cells. (A-C)-ultrathin sections in TEM. ( $\left.\mathbf{A}^{\prime}-\mathbf{C}^{\prime}\right)$-light microscopy of Hoechst labeling (blue) shown superimposed on DIC image (left) and separately (right). (A) - an early stage of crystal cell development characterized by a very small crystal ( $<800 \mathrm{~nm}$ ), rounded nucleus, and elongated shape of the cell. Inset is a magnified boxed region, showing a vacuole with a growing crystal. $\left(\mathbf{A}^{\prime}\right)$ - a crystal cell at the same stage as shown in (A), with a small crystal and bean-shaped nucleus. (B) - the crystal becomes larger, the nucleus adheres to the cell membrane and begins to adopt cup shape, and the cell rounds up. (B') —a stage corresponding to (B) when the nucleus starts to bend. (C) - mature crystal cell with a large crystal occupying the entire volume of the vacuole and a thin cup-shaped nucleus. $\left(\mathbf{C}^{\prime}\right)$ - mature crystal cell corresponding to that in $(\mathbf{C})$ with a large crystal and a very thin nucleus. $\mathrm{c}-$ crystal, $\mathrm{m}$ - mitochondrion, $\mathrm{n}-$ crystal cell nucleus, $\mathrm{p}-$ crystal cell protrusions, $\mathrm{v}$ - vacuole with growing crystal.

The main morphological characteristics of a differentiating crystal cell are: (i) a smaller crystal floating inside a vacuole containing a substance that is electron lucent and homogeneous; (ii) a bean-shaped rather than cup-shaped nucleus and (iii) elongated rather than round shape of the cell. Acquisition of the mature phenotype involves growth of the crystal, reshaping of the nucleus and cell body and repositioning and removal of organelles.

Distribution of crystals of different size. Crystal cells are distributed along the rim of the animal and absent from central regions of the body $[3,18]$. Measurement of the distance from the body edge to individual crystals $(n=189)$ indicates that crystal cells are scattered within a concentric region starting approximately $15 \mu \mathrm{m}$ from the edge and spreading inside up to $120 \mu \mathrm{m}$ from the edge (Figure 2A). Within this belt-like zone, smaller crystals selectively occupy the deeper region, while large crystals are located closer to the periphery (Figure 2A,B). Indeed, there is a negative correlation between the size of a crystal and its distance from the rim of the body (Spearman's $\mathrm{r}_{\mathrm{s}}=-0.55, p=3.76 \times 10^{-16}$; homoscedasticity was confirmed with Breusch Pagan test giving a $p$ value of 0.66 ).

Attempt to identify organic matrix for crystal biomineralization. To seek molecular signatures of an organic scaffold employed by crystal cells for biomineralization, several dyes were applied to decalcified tissues of Trichoplax: calcofluor white, a dye that binds chitin; Col-F dye, a stain for collagen and a cocktail of seven lectins with affinity to different sugar moieties. None of the dyes bind to material at sites of decalcified crystals (red arrowheads in Figure 3A-C), although some lectins label nuclear envelopes (Figure 3C). 
A

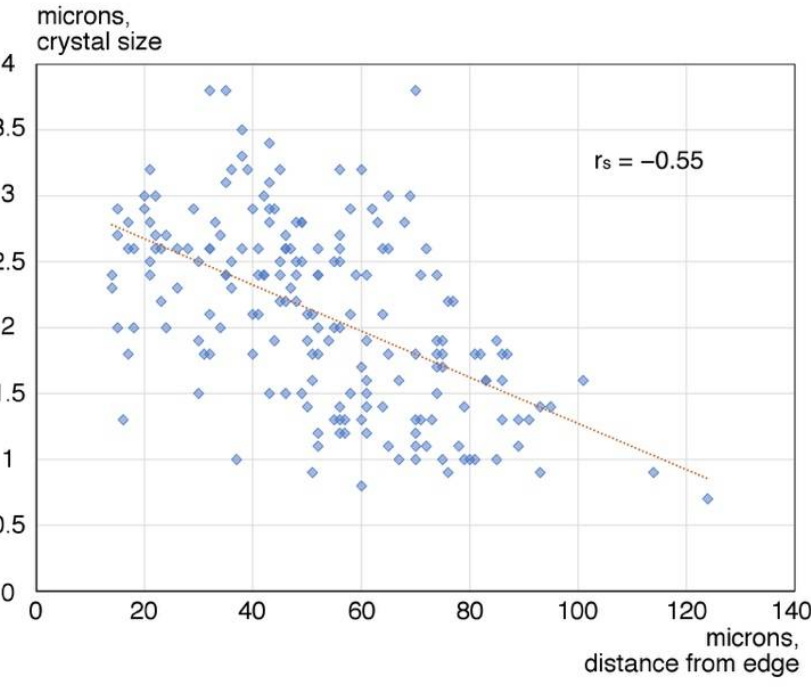

B
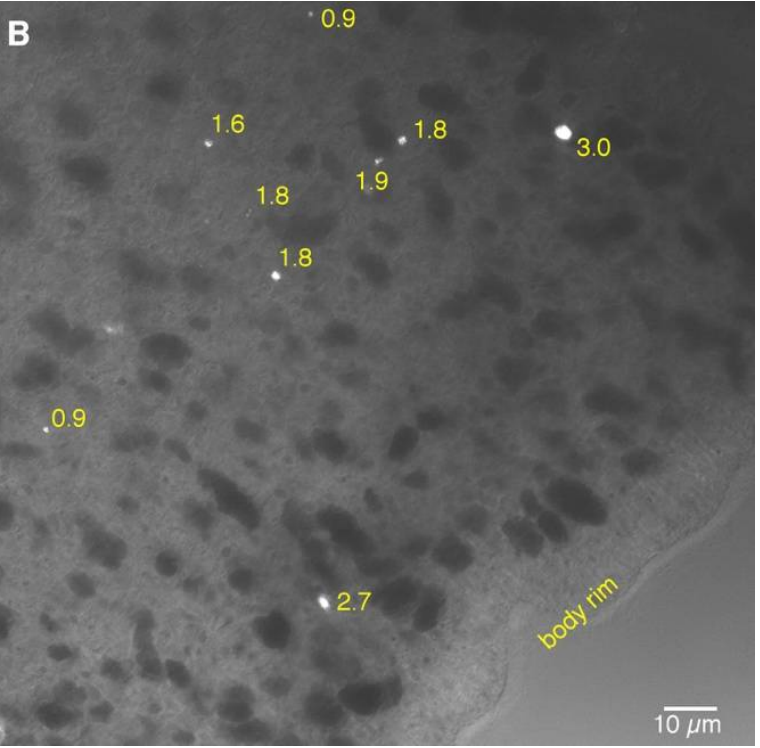

Figure 2. Distance from the rim of the animal of crystals of different size. (A)—dot plot showing individual crystal sizes at varying distances from the rim (blue semi-transparent diamonds; $N$ crystals $=189 ; N$ animals $=8$ ) and linear trend line (red). (B)-DIC image of marginal zone of Trichoplax body showing a group of crystals; size of each crystal is indicated in microns. Smaller crystals lie deeper while larger crystals lie closer to the periphery.
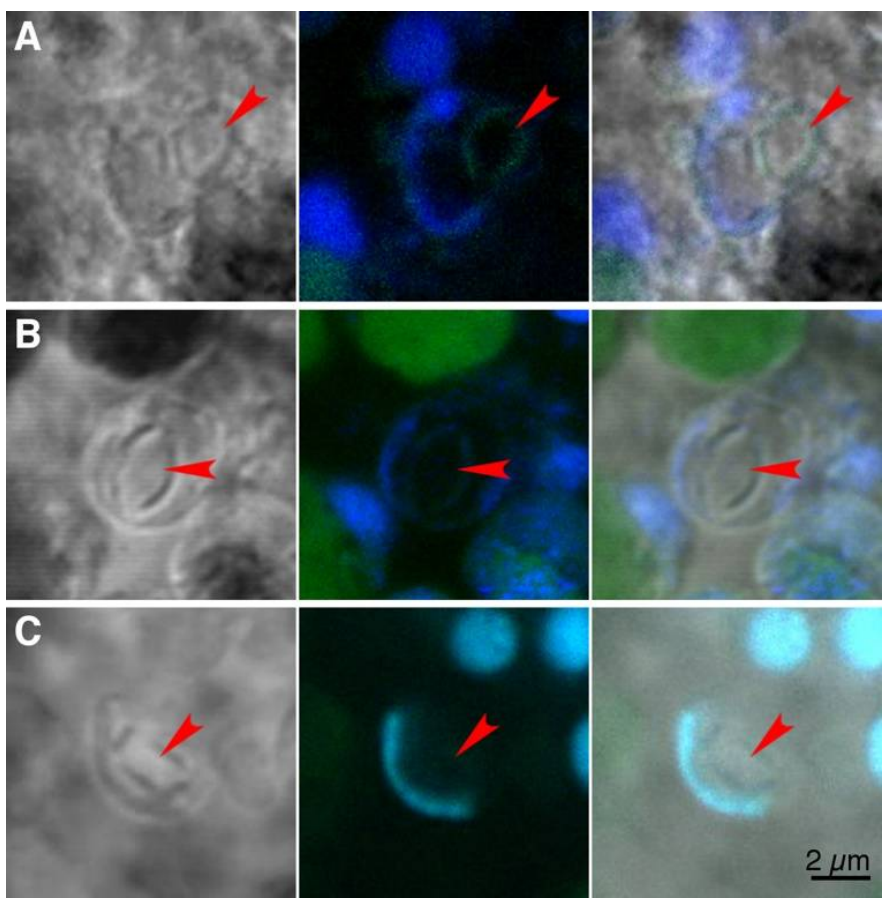

Figure 3. Fluorescence labeling (green) for potential components of organic matrix for crystal precipitation. Decalcified tissue was labeled with calcofluor white (A), Col-F (B) and a cocktail of lectins (C). Nuclear labeling (Propidium iodide in A and Hoechst in B and C) is blue. Left panel in each row shows an image in transmitted light, middle panel is merged fluorescence channels (maximum intensity projection through crystal cell thickness) and right panel is fluorescence channels superimposed on the transmitted light image. Arrowheads point at the site of a decalcified crystal. The scale bar is applicable to all images. 


\section{Discussion}

We describe stages in the differentiation of placozoan crystal cells, a cell type implicated in gravity reception. Maturation of crystal cells involves growth of a crystal within a membrane enclosed vacuole, dramatic changes in the shape and position of the nucleus, reshaping of the cell body and extension of small protrusions, repositioning and removal of organelles, and cell displacement towards the rim. During maturation, they likely also establish their interactions with fiber cells and rim epithelial cells as described previously [18]. Crystal cell differentiation apparently occurs constitutively because most animals have a row of cells containing large crystals around their entire circumference as well as cells containing smaller crystals and located further from the rim. Nascent crystal cells do not contain specialized organelles that are features of other somatic cell types (dorsal and ventral epithelial cells, fiber cells, lipophil cells, and gland cells) so we hypothesize that they are generated by undifferentiated mitotic cells, which are prevalent throughout the body $[17,30]$.

Cells involved in biomineralization in many animal lineages precipitate hard material in extracellular space. Cells precipitating hard material internally are rare and present in phylogenetically distant animal groups. These include scleroblasts in some corals [31,32] and lithocytes in Acoela [27,33,34], Xenoturbella [28], Ctenophore [35] and echinoderms [36]. Some unicellular organisms precipitate hard material intracellularly that is subsequently deposited extracellularly [37]. The patchy phylogenetic distributions of animals having cells with intracellular biomineralization is indicative of independent evolution of this cell type; likewise, the cells providing gravireceptions are thought not to share a common evolutionary origin [38]. Even within monophyletic clades, lithocytes are thought to have evolved independently in different lineages [28]. A feature that is shared between all of these various cell types is that internal biomineralization takes place within an intracellular vacuole. The membrane of this vacuole is thought to have a rich repertoire of ion pumps, transporters and exchangers [31,37]. Some lithocytes have mitochondria adhered to the crystal $[39,40]$. In placozoan crystal cells, both immature and mature, mitochondria surround the vacuole enclosing the crystal $([3,18]$; present study) suggesting that mitochondria could be essential for biomineralization process. Perhaps they supply carbonate ions, as was shown in other calcifying non-bilaterians: sponges [41] and corals [42].

Information about the differentiation of cells with internal mineralization is sparse. Lithocytes of juvenile acoels are reported to have statoliths that are smaller and softer than those in mature animals [34]. In Trichoplax, a small growing crystal in a differentiating crystal cell is already hard as is evident because the crystal falls out during thin sectioning.

In most biomineralizing animals, hard inorganic material precipitates on an organic scaffold which guides crystallization in order to finally form a structure with specific characteristics (shape, ductility, density, hardness, and others) (reviewed by [43]). This organic scaffold often has a complex architecture and is composed of different molecules such as polysaccharides (i.e., chitin), collagen, proteoglycans, and small acidic proteins [44-47]. Our histochemical attempts to detect the epitopes of some of these molecules (chitin, collagen, and carbohydrate residues of proteoglycans) in the organic compartment of a crystal failed to identify a possible scaffold. Genome analysis revealed a very low level of proteins with high rate of negatively charged amino acid residues in Trichoplax [42], and transcriptome analysis did not reveal homologs of small acidic proteins in placozoans [48]. As placozoans lack scaffolding molecules involved in biomineralization in other animals, they may use a novel substrate, or cope with mineralization without any organic matrix.

Crystals of smaller size, that is, belonging to immature crystal cells, lay deeper inside the animal body than the bigger crystals. This difference suggests that immature crystal cells, apart from changing morphology, experience spatial displacement towards the periphery during differentiation. The mechanism of displacement is unknown; EM observations of crystal cell processes showed no evidence of motility [18]. Alternatively, crystal growth and crystal cell differentiation could be impeded in crystal cells differentiating 
farther from the animal rim. In addition to crystal cells, several other cell types in Trichoplax have distinct concentric spatial distributions $[14,15]$. The control of differentiation and positional information may be provided by multiple transcriptional factors with distinct expression patterns across the Trichoplax body [49-51].

The present research provides the first description of how one of the somatic cell types in Placozoa acquires its distinctive phenotype. Crystal cell differentiation involves a complex sequence of structural changes and utilization of biochemical processes that result in the formation of a hard intravacuolar crystal that we assume is critical for its proposed function as a gravity receptor. Much remains to be learned about biomineralization in crystal cells as well as about the sensory transduction mechanisms and signaling pathways involved in gravireception. A promising approach would be to use RNAseq techniques to characterize expression profile in crystal cells. A single cell RNAseq study of Trichoplax revealed multiple cell clusters, many of which could be assigned to specific morphological cell types [52]. However, no cluster was associated with crystal cells, possibly because crystal cells are the least prevalent cell type, making clustering hard to define. For further studies, samples enriched in crystal cells should be obtained; this could be achieved by selective collection of crystal cells based on their distinctive features, such as the possession of a birefringent crystal, and perhaps lower buoyancy than other cell types.

Funding: The work was supported by the Intramural Research Program of the National Institute of Neurological Disorders and Stroke and the National Institutes of Health.

Institutional Review Board Statement: Not applicable.

Informed Consent Statement: Not applicable.

Data Availability Statement: All data generated during the research are shown in the manuscript.

Acknowledgments: I am grateful to Carolyn L. Smith and Thomas S. Reese (NINDS, NIH) for advice and help in preparing the manuscript and for English proofreading.

Conflicts of Interest: I declare that I have no competing interests.

\section{References}

1. Schulze, F.E. Trichoplax adhaerens, nov. gen., nov. spec. Zool. Anz. 1891, 6, 92-97.

2. Grell, K.G.; Ruthmann, A. Placozoa. In Microscopic Anatomy of Invertebrates, Volume 2: Placozoa, Porifera, Cnidaria, and Ctenophora; Harrison, F.W., Westfall, J.A., Eds.; Wiley-Liss: New York, NY, USA, 1991; pp. 13-27.

3. Smith, C.L.; Varoqueaux, F.; Kittelmann, M.; Azzam, R.N.; Cooper, B.; Winters, C.A.; Eitel, M.; Fasshauer, D.; Reese, T.S. Novel cell types, neurosecretory cells, and body plan of the early-diverging metazoan Trichoplax adhaerens. Curr. Biol. 2014, 24, 1565-1572. [CrossRef]

4. Smith, C.L.; Pivovarova, N.; Reese, T.S. Coordinated feeding behavior in Trichoplax, an animal without synapses. PLoS ONE 2015, 10, e00822-17. [CrossRef]

5. Schierwater, B.; DeSalle, R. Placozoa. Curr. Biol. 2018, 28, R97-R98. [CrossRef]

6. Smith, C.L.; Reese, T.S.; Govezensky, T.; Barrio, R.A. Coherent directed movement toward food modeled in Trichoplax, a ciliated animal lacking a nervous system. Proc. Natl. Acad. Sci. USA 2019, 116, 8901-8908. [CrossRef]

7. Dunn, C.W.; Hejnol, A.; Matus, D.Q.; Pang, K.; Browne, W.E.; Smith, S.A.; Seaver, E.; Rouse, G.W.; Obst, M.; Edgecombe, G.D.; et al. Broad phylogenomic sampling improves resolution of the animal tree of life. Nature 2008, 452, 745-749. [CrossRef]

8. Moroz, L.L.; Kocot, K.M.; Citarella, M.R.; Dosung, S.; Norekian, T.P.; Povolotskaya, I.S.; Grigorenko, A.P.; Dailey, C.; Berezikov, E.; Buckley, K.M.; et al. The ctenophore genome and the evolutionary origins of neural systems. Nature 2014, 510, 109-114. [CrossRef]

9. Pett, W.; Adamski, M.; Adamska, M.; Francis, W.R.; Eitel, M.; Pisani, D.; Wörheide, G. The role of homology and orthology in the phylogenomic analysis of metazoan gene content. Mol. Biol. Evol. 2019, 36, 643-649. [CrossRef] [PubMed]

10. Simion, P.; Philippe, H.; Baurain, D.; Jager, M.; Richter, D.J.; Di Franco, A.; Roure, B.; Satoh, N.; Quéinnec, É.; Ereskovsky, A.; et al. A large and consistent phylogenomic dataset supports sponges as the sister group to all other animals. Curr. Biol. 2017, 27, 958-967. [CrossRef] [PubMed]

11. Ruthmann, A.; Behrendt, G.; Wahl, R. The ventral epithelium of Trichoplax adhaerens (Placozoa): Cytoskeletal structures, cell contacts and endocytosis. Zoomorphology 1986, 106, 115-122. [CrossRef]

12. Smith, C.L.; Reese, T.S. Adherens junctions modulate diffusion between epithelial cells in Trichoplax adhaerens. Biol. Bull. 2016, 231, 216-224. [CrossRef]

13. Smith, C.L.; Mayorova, T.D. Insights into the evolution of digestive systems from studies of Trichoplax adhaerens. Cell Tissue Res. 2019, 377, 353-367. [CrossRef] 
14. Mayorova, T.D.; Hammar, K.; Winters, C.A.; Reese, T.S.; Smith, C.L. The ventral epithelium of Trichoplax adhaerens deploys in distinct patterns cells that secrete digestive enzymes, mucus or diverse neuropeptides. Biol. Open 2019, 8, bio045674. [CrossRef]

15. Varoqueaux, F.; Williams, E.A.; Grandemange, S.; Truscello, L.; Kamm, K.; Schierwater, B.; Jékely, G.; Fasshauer, D. High Cell Diversity and Complex Peptidergic Signaling Underlie Placozoan Behavior. Curr. Biol. 2018, 28, 3495-3501.e2. [CrossRef]

16. Rassat, J.; Ruthmann, A. Trichoplax adhaerens F.E. Schulze (placozoa) in the scanning electron microscope. Zoomorphologie 1979, 93, 59-72. [CrossRef]

17. Mayorova, T.D.; Hammar, K.; Jung, J.H.; Aronova, M.A.; Zhang, G.; Winters, C.A.; Reese, T.S.; Smith, C.L. Placozoan fiber cells: Mediators of innate immunity and participants in wound healing. Nat. Sci. Rep. 2021, Submitted.

18. Mayorova, T.D.; Smith, C.L.; Hammar, K.; Winters, C.A.; Pivovarova, N.B.; Aronova, M.A.; Leapman, R.D.; Reese, T.S. Cells containing aragonite crystals mediate responses to gravity in Trichoplax adhaerens (Placozoa), an animal lacking neurons and synapses. PLoS ONE 2018, 13, e0190905. [CrossRef] [PubMed]

19. Signorovitch, A.Y.; Dellaporta, S.L.; Buss, L.W. Molecular signatures for sex in the Placozoa. Proc. Natl. Acad. Sci. USA 2005, 102, 15518-15522. [CrossRef]

20. Schierwater, B. My favorite animal, Trichoplax adhaerens. BioEssays 2005, 27, 1294-1302. [CrossRef] [PubMed]

21. Srivastava, M.; Begovic, E.; Chapman, J.; Putnam, N.H.; Hellsten, U.; Kawashima, T.; Kuo, A.; Mitros, T.; Salamov, A.; Carpenter, M.L.; et al. The Trichoplax genome and the nature of placozoans. Nature 2008, 454, 955-960. [CrossRef] [PubMed]

22. Zuccolotto-Arellano, J.; Cuervo-González, R. Binary fission in Trichoplax is orthogonal to the subsequent division plane. Mech Dev. 2020, 162, 103608. [CrossRef]

23. Schierwater, B.; Osigus, H.J.; Bergmann, T.; Blackstone, N.W.; Hadrys, H.; Hauslage, J.; Humbert, P.O.; Kamm, K.; Kvansakul, M.; Wysocki, K.; et al. The enigmatic Placozoa part 1: Exploring evolutionary controversies and poor ecological knowledge. BioEssays 2021, 43, 2100080. [CrossRef] [PubMed]

24. Von Der Chevallerie, K.; Rolfes, S.; Schierwater, B. Inhibitors of the p53-Mdm2 interaction increase programmed cell death and produce abnormal phenotypes in the placozoon Trichoplax adhaerens (F.E. Schulze). Dev. Genes Evol. 2014, 224, 79-85. [CrossRef]

25. Romanova, D.Y.; Smirnov, I.V.; Nikitin, M.A.; Kohn, A.B.; Borman, A.I.; Malyshev, A.Y.; Balaban, P.M.; Moroz, L.L. Sodium action potentials in placozoa: Insights into behavioral integration and evolution of nerveless animals. Biochem. Biophys. Res. Commun. 2020, 532, 120-126. [CrossRef]

26. Schierwater, B.; Osigus, H.J.; Bergmann, T.; Blackstone, N.W.; Hadrys, H.; Hauslage, J.; Humbert, P.O.; Kamm, K.; Kvansakul, M.; Wysocki, K.; et al. The enigmatic Placozoa part 2: Exploring evolutionary controversies and promising questions on earth and in space. BioEssays 2021, 43, 2100083. [CrossRef] [PubMed]

27. Ferrero, E. A Fine Structural Analysis of the Statocyst in Turbellaria Acsela. Zool. Scr. 1973, 2, 5-16. [CrossRef]

28. Ehlers, U. Comparative morphology of statocysts in the Plathelminthes and the Xenoturbellida. Hydrobiologia 1991, 227, 263-271. [CrossRef]

29. Jackson, A.M.; Buss, L.W. Shiny spheres of placozoans (Trichoplax) function in anti-predator defense. Invertebr. Biol. 2009, 128, 205-212. [CrossRef]

30. Romanova, D.Y.; Varoqueaux, F.; Daraspe, J.; Nikitin, M.A.; Eitel, M.; Fasshauer, D.; Moroz, L.L. Hidden cell diversity in Placozoa: Ultrastructural insights from Hoilungia hongkongensis. Cell Tissue Res. 2021, 385, 623-637. [CrossRef]

31. Watabe, N.; Kingsley, R.J. Calcification in Octocorals. In Hard Tissue Mineralization and Demineralization; Suga, S., Watabe, N., Eds.; Springer: Tokyo, Japan, 1992; pp. 127-147.

32. Conci, N.; Vargas, S.; Wörheide, G. The Biology and Evolution of Calcite and Aragonite Mineralization in Octocorallia. Front. Ecol. Evol. 2021, 9, 623774. [CrossRef]

33. Achatz, J.G.; Martinez, P. The nervous system of Isodiametra pulchra (Acoela) with a discussion on the neuroanatomy of the Xenacoelomorpha and its evolutionary implications. Front. Zool. 2012, 9, 27. [CrossRef]

34. Sakagami, T.; Watanabe, K.; Ikeda, R.; Ando, M. Structural analysis of the statocyst and nervous system of Praesagittifera naikaiensis, an acoel flatworm, during development after hatching. Zoomorphology 2021, 140, 183-192. [CrossRef]

35. Tamm, S.L. Functional consequences of the asymmetric architecture of the ctenophore statocyst. Biol. Bull. 2015, 229, 173-184. [CrossRef]

36. Ehlers, U. Ultrastructure of the statocysts in the apodous sea cucumber Leptosynapta inhaerens (Holothuroidea, Echinodermata). Acta Zool. 1997, 78, 61-68. [CrossRef]

37. Taylor, A.R.; Chrachri, A.; Wheeler, G.; Goddard, H.; Brownlee, C. A voltage-gated H+ channel underlying $\mathrm{pH}$ homeostasis in calcifying Coccolithophores. PLoS Biol. 2011, 9, e1001085. [CrossRef] [PubMed]

38. Moroz, L.L. On the independent origins of complex brains and neurons. Brain. Behav. Evol. 2009, 74, 177-190. [CrossRef] [PubMed]

39. Ferrero, E.A.; Bedini, C. Ultrastructural aspects of nervous-system and statocyst morphogenesis during embryonic development of Convoluta psammophila (Turbellaria, Acoela). Hydrobiologia 1991, 227, 131-137. [CrossRef]

40. Rohde, K.; Watson, N.; Faubel, A. Ultrastructure of the Statocyst in an Undescribed Species of Luridae (Platyhelminthes, Rhabdocoela, Luridae). Aust. J. Zool. 1993, 41, 215-224. [CrossRef]

41. Voigt, O.; Adamski, M.; Sluzek, K.; Adamska, M. Calcareous sponge genomes reveal complex evolution of $\alpha$-carbonic anhydrases and two key biomineralization enzymes. BMC Evol. Biol. 2014, 14, 1-19. [CrossRef] 
42. Bhattacharya, D.; Agrawal, S.; Aranda, M.; Baumgarten, S.; Belcaid, M.; Drake, J.L.; Erwin, D.; Foret, S.; Gates, R.D.; Gruber, D.F.; et al. Comparative genomics explains the evolutionary success of reef-forming corals. Elife 2016, 5, e13288. [CrossRef] [PubMed]

43. Simkiss, K.; Wilbur, K.M. The Control of Mineralization. In Biomineralization; Academic Press Inc.: San-Diego, CA, USA, 1989; pp. 42-57.

44. Marin, F.; Luquet, G. Unusually Acidic Proteins in Biomineralization. In Handbook of Biomineralization: Biological Aspects and Structure Formation; Bäuerlein, E., Ed.; Wiley-VCH Verlag GmbH \& Co. K: Hoboken, NJ, USA, 2007; pp. 273-290. ISBN 9783527316410.

45. Arias, J.L.; Fernández, M.S. Polysaccharides and proteoglycans in calcium carbonate-based Biomineralization. Chem. Rev. 2008, 108, 4475-4482. [CrossRef]

46. Ehrlich, H. Chitin and collagen as universal and alternative templates in biomineralization. Int. Geol. Rev. 2010, 52, 661-699. [CrossRef]

47. Nudelman, F.; Lausch, A.J.; Sommerdijk, N.A.J.M.; Sone, E.D. In vitro models of collagen biomineralization. J. Struct. Biol. 2013, 183, 258-269. [CrossRef]

48. Conci, N.; Wörheide, G.; Vargas, S. New non-bilaterian transcriptomes provide novel insights into the evolution of coral skeletomes. Genome Biol. Evol. 2019, 11, 3068-3081. [CrossRef] [PubMed]

49. Martinelli, C.; Spring, J. Distinct expression patterns of the two T-box homologues Brachyury and Tbx2/3 in the placozoan Trichoplax adhaerens. Dev. Genes Evol. 2003, 213, 492-499. [CrossRef]

50. Hadrys, T.; DeSalle, R.; Sagasser, S.; Fischer, N.; Schierwater, B. The trichoplax PaxB gene: A putative proto-Paxa/B/C gene predating the origin of nerve and sensory cells. Mol. Biol. Evol. 2005, 22, 1569-1578. [CrossRef] [PubMed]

51. Dubuc, T.Q.; Ryan, J.F.; Martindale, M.Q. “Dorsal-Ventral” Genes Are Part of an Ancient Axial Patterning System: Evidence from Trichoplax adhaerens (Placozoa). Mol. Biol. Evol. 2019, 36, 966-973. [CrossRef]

52. Sebé-Pedrós, A.; Chomsky, E.; Pang, K.; Lara-Astiaso, D.; Gaiti, F.; Mukamel, Z.; Amit, I.; Hejnol, A.; Degnan, B.M.; Tanay, A. Early metazoan cell type diversity and the evolution of multicellular gene regulation. Nat. Ecol. Evol. 2018, 2, 1176-1188. [CrossRef] [PubMed] 